\title{
Application Design of an Integrated Outdoor Air Quality Monitoring Device Based on Solar Power
}

\author{
Wang Yiwang ${ }^{1,2, a}$, Ni Youshun $^{2}$,Dong Xiaoxiao ${ }^{2}$, Cang Xiang $^{2}$, Zhang Jili $^{2}$ and \\ Zhang Shuai ${ }^{3}$,Hai Chen ${ }^{4}$ \\ ${ }^{1}$ Suzhou Vocational University, Suzhou Jiangsu 215104, China \\ ${ }^{2}$ Jiangsu Engineering Research Center for PV Generation, Suzhou Jiangsu 215104, China \\ ${ }^{3}$ Suzhou Hosola New Energy Co., Ltd.,Suzhou 215123,China \\ ${ }^{4}$ Suzhou Institute of Measurement and Testing Technology, Suzhou 215121, China \\ awyiwang@163.com
}

Keywords: Solar power ; air quality; moitor device; integrated system.

Abstract. According to the new application requirements of outdoor air quality monitoring system,a novel outdoor air quality device was designed in this paper.The device utilizes solar power supply, combined with digital control, wireless communications, LED display and other technologies, to realize air quality multi-parameter real-time monitoring.The hardware components and software implementations of device are described in detail,using an integrated design concept, an experimental prototype test system was developed,the verification experiments on the prototype were conducted, experimental results showed that the device can achieve accurate real-time online monitoring of air quality, which can be suitable for application in a variety of outdoor occasions.

\section{Introduction}

In recent years, with the continuous improvement of living standards, people living standards increasingly more attention to the surrounding air quality, the demand for environmental information is also increasing[1-2].

Using modern technology to develop a variety of different air quality monitoring devices, to meet the actual demand for air quality monitoring[3-8].For the occasion outdoor air quality monitoring devices and other applications, the conventional power needs rewiring, which limit the scope and certain extent of application flexibility.The use of some new power supply based on new energy, can make up for deficiencies, and has advantages of energy saving and environmental protection, etc[9-11].In this paper, a novel outdoor air quality device was designed. The device can be easily mounted on street lights, signs pole and so on, with application convenient, space-saving advantages.

\section{Overall structure of the device}

The overall structure of integrated solar powered outdoor air quality monitoring device system is shown in Fig.1. Solar module and monitoring control cabinet composed of integrated design, and the LED display with removable independent modular design, which depending on the application to facilitate the needs of different occasions, different options in different ways to install. In the system module, a wireless communication unit can be optional, implementation and monitoring system, intelligent terminals and other wireless network, network monitoring.

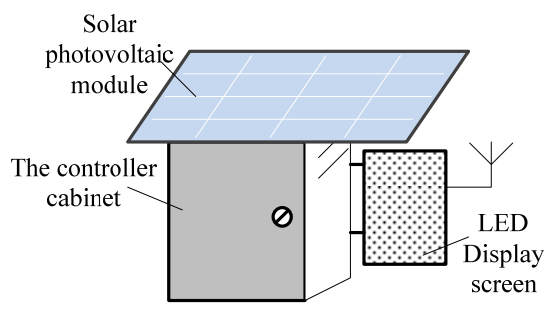

Figure 1. The composition diagram of system outside structure 
The entire system circuit structure as shown in Fig.2, monitoring system use dual control chips design, which is the main control chip and LED display control chip designed separately, which using serial communication between the two chips. The entire circuit structure can be divided into solar power supply circuit, the main control circuit unit and a display control circuit of three parts, wherein the solar power supply circuit to provide a stable DC power for the entire device; the master unit completed air quality multi-parameter acquisition and processing, real-time clock RTC processing, LCD display driver control, the keys input interface processing functions and power supply monitoring, then control the collected data of air quality to the multi-parameter display control chip through the serial communication; display control chip to complete the main LED display driver information display control, and a wireless communication function.

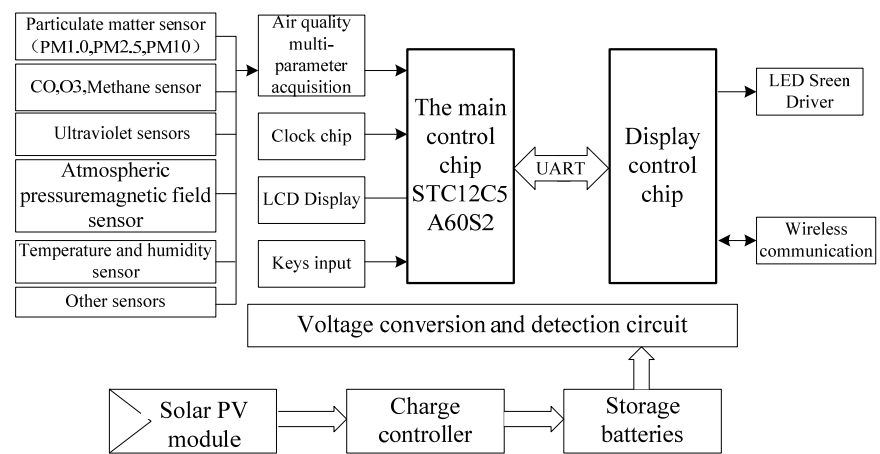

Figure 2. The block diagram of circuits

\section{Hardware system design}

Solar power supply unit[12-14].For outdoor applications, use a separate solar power system can be unrestricted conventional mains supply, device installation flexibility, in addition, energy saving. Solar module power emitted via a dedicated charge controller to charge the battery, and then the DC / DC converter is converted into stable DC power supply for the entire system unit.

Solar PV module capacity can use the daily generating capacity Qpv according to formula (1) is calculated:

$$
\mathrm{Q}_{p v}=K_{t} \times I_{m} \times H \times \eta(\mathrm{Ah})
$$

Where: K stands for the comprehensive correction coefficient, which includes ramps attenuation correction and environmental components of other comprehensive correction coefficient; Im is the

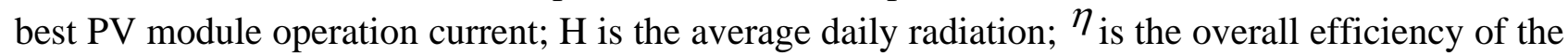
system.The battery capacity according to the formula (2) calculated as follows:

$$
\mathrm{Q}_{b a t}=K_{A} \times Q_{a l} \times N_{r}(\mathrm{Ah})
$$

Where: KA is comprehensive correction coefficient for the battery, including battery tilization, the battery capacity and depth of discharge attenuation coefficient and other factors; Qal design means the total daily consumption; $\mathrm{Nr}$ is maximum rain (or no effective illumination) for several days.

Combined with the requirements of device system operating power and continuous reliable operation.Solar module selected $30 \mathrm{~W}$ polycrystalline silicon solar panels, solar module main parameters are: Uoc21.1V, Isc1.91A, Um17.2V, Im1.72A. Battery selected 12V / 20Ah maintenance-free lead-acid batteries. Drop by dedicated highly efficient DC / DC step-down module, the battery voltage of $12 \mathrm{~V}$ / step-down conversion means to provide DC5V control of power.

Master control unit design. Master control unit uses MCU STC12C5A60S2 as the main control chip, each sensor uses a modular design.STC12C5A60S2 MCU master control system schematic shown in Fig.3, STC12C5A60S2 is a new single-chip high-speed enhanced 8051 core, the MCU has a wealth of on-chip peripheral interfaces and resources to meet the performance requirements of the control device[12-13]. 


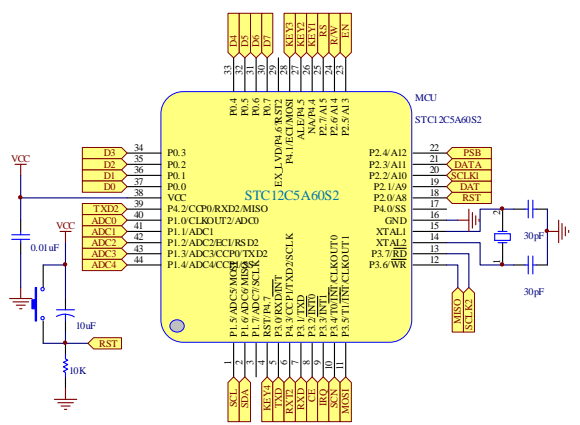

Figure 3.Master control MCU system circuit schematics

The air quality monitoring data of air quality monitoring system including particulate matter (PM), combustible gases, toxic gases, ultraviolet radiation, atmospheric pressure and temperature and humidity and other common air quality qualitative parameters, the overall system are modular design.The sensors through corresponding interface to a master microcontroller.

LED display unit design.Bright LED display can display dynamic parameters information of air quality, which can also play information publishing. The designed display uses two P5LED screen components.Display driven by a separate STC12C5A60S2 control chip, and the main control circuit unit can be used between the serial UART or wireless means to exchange information. The display part received from the master unit air quality multi-parameter acquisition and processing of information, then real-time scrolling display LED screen. The main screen displays real-time information and dynamic air quality information.

System software design.The control software designed and developed using the $C$ language to write based on Keil C51 integrated development environment, the program's main control program consisting of software structure shown in Fig.4.

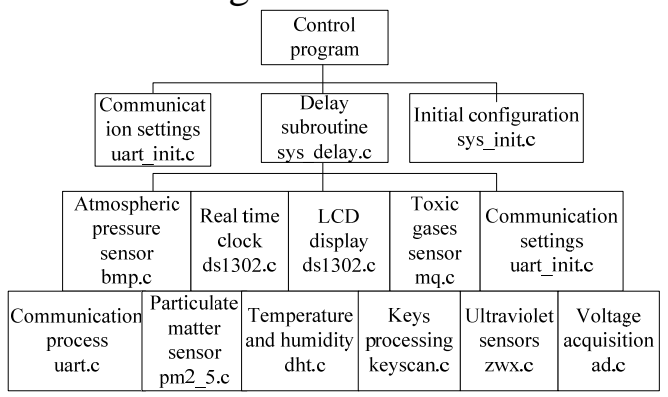

Figure 4. The main program composition structure diagram

\section{Experimental Test and application}

A prototype device system was design and development, Prototype and application shown in Fig.5, the prototype operation experiments were studied and tested by analysis of test results and the corresponding control experiments, indicating that the unit is stable and reliable, according to the design requirements can accurately monitor the various air quality parameters.

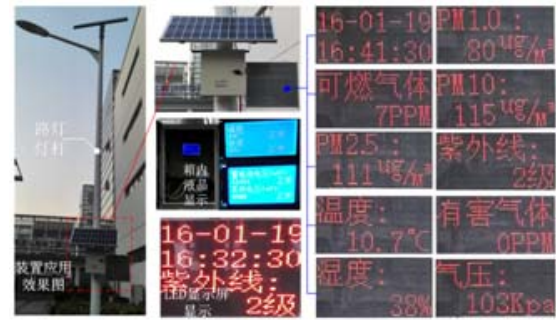

Figure 5. The practical effect of outdoor applications

\section{Summary}

In this paper, the design and development of integrated outdoor air quality monitoring devices based on solar-powered. The designed device used green solar-powered and integrated design ideas, 
combined with digital control technology, a variety of air quality parameters in real-time online collection, and scrolling display through the LCD screen, which can satisfy the application of outdoor air quality monitoring occasions, with high market application value.

\section{Acknowledgements}

This work was partly supported by the Jiangsu Training Programs of Innovation and Entrepreneurship for University Student (201511054023H), the Qing Lan Project, "12th Five-Year" plan project 2015 annual project of Jiangsu Open Unviersity(15SEW-Q-054),Science and Technology Planning Project of Suzhou City(SS201520 and SS201503). Foundation project of Suzhou Vocational University.

\section{References}

[1] DENG Jia, WANG Xian zhe. Design of the Remote Air Quality Monitor System Based on GSM[J]. OPTICS\& OPTOFLFCTRONICTCHNOLOGY, ,2015,13(2):72-75.

[2] HOU Peiguo, LEI Qiaoling.Design of the air quality monitoring system based on WSN[J]. Industrial Instrumentation \& Automation,2009 (3):109-112.

[3] WAN Li1,JIAO Xuguang. Design of Urban Air Quality Monitoring System Based on WSN[J].Electrical \& Energy Management Technology ,2014 (16):47-49.

[4] Lu Chao.Distributed Wireless Monitoring System for Air Quality [J]. PROCESS AUTOMATION INST R UMENTATION,2014,35 (4):54-60.

[5] Wei Dexian,Chen Haicong,Huang Zichun,et al. Design of Air Quality Monitoring System with PV/Wind Complementary Power Supply [J]. PROCESS AUTOMATION INSTRUMENTATION, 2014,35 (8):86-90.

[6] Wang Haibao,Wu Tingting,Wu Guangjie. Air Quality Monitoring System Based on LabVIEW[J]. Computer Measurement \& Control,2011,9(3):525-527.

[7] Zhang Ximin.Design of Ambient Air Quality Monitoring System Based on SMS[J]. China Instrumentation ,2006(10):49-51.

[8] CHENG Man,YUAN Hong-bo,GAO Li-ai. Greenhouse wireless sensor network precise monitoring system based on solar power supplying[J]. Guangdong Agricultural Sciences, 2013(3):179-181.

[9] LONU Ying, ZHANU Li. Environmental intelligent monitoring system for greenhouse based on solar power supply[J]. Modern Electronics Technique, 2012,35(2):198-200.

[10]DUAN Ying-hong,WANG Chang,GAO Ming-hui,WANG Xue-qing. Water Aerator System Based on Solar Energy[J]. Automation \& Instrumentation, 2013(6):53-56.

[11]SU Cheng-ren, CHEN Zheng-wu, HU Fang-lin, LIANG Sheng-de. Optimization design of independent photovoltaic supply system for GSM repeaters[J]. Chinese Journal of Power Sources, 2013,137(10):1779-1780.

[12] Information on http://www.stcmcu.com.

[13]YU Chi-ye,SONG Yue, LEI Rui-ting. Intelligent Tracking Car Based on STC12C5A60S2[J]. RESEARCH AND EXPLORATION IN LABORATORY,2014,33(11):46-49.

[14]Zheng Xi,Zhou Jinzhi,Kang Chunxiang. The wireless air quality monitor system based on embedded Web server[J].Application of Electronic Technique,2015,41(5):39-42. 